\title{
Prevalence and Characterization of Extended Spectrum Beta-Lactamase Production in Clinical Isolates of Klebsiella pneumonia
}

\author{
Begum Fouzia ${ }^{1 *}$ and Damle AS $^{2}$ \\ ${ }^{1}$ Department of Microbiology, Shadan Institute of Medical Sciences, Hyderabad, India \\ ${ }^{2}$ Department of Microbiology, Govt. Medical College and Hospital, Aurangabad, India
}

\begin{abstract}
Aim: This study was carried out to determine the presence of TEM and SHV genes in extended- spectrum $\beta$-lactamase (ESBL) producing Klebsiella pneumoniae. The study was also aimed to compare results of phenotypic confirmatory double disc diffusion test and genotypic methods.

Materials and Methods: A total of 679 strains of Klebsiella pneumoniae were selected for the study from June 2012-December 2013. Kirby - Bauer disk diffusion method was performed to determine the antibiotic resistance pattern. Screened for ESBL and confirmed by phenotypic confirmatory disc diffusion test (PCDDT). 100 randomly selected isolates were investigated for the presence of TEM and SHV genes via Polymerase chain reaction (PCR) using two different sets of primers. Multiplex PCR was also performed for the same.

Results: Phenotypic confirmatory test was able to detect ESBL production in $90.13 \%$ of Klebsiella pneumoniae isolates. Among the two ESBL genotypes, the most prevalent genotype was found to be TEM. Majority of ESBL producing isolates possess both ESBL genes.

Conclusion: Multiplex PCR can be used as a rapid method to identify common genes (TEM and SHV) responsible for extended spectrum beta lactamase production in Klebsiella pneumoniae. It will prove valuable for surveillance and for determining the line of treatment against drug resistant organisms, thus saving precious time and resources. PCDDT results correlated with genotypic method in all the tested strains.
\end{abstract}

\section{Keywords: ESBL; Klebsiella pneumonia; TEM; SHV}

\section{Introduction}

Microbes are remarkably adaptable and amazingly versatile. Through the course of evolution; they have developed sophisticated mechanisms for preserving genetic information and disseminating it efficiently in the interests of their survival. They recognize no boundaries. The resistance developed in one part of the country or indeed in the world can be disseminated readily [1]. Emergence of resistance to $\beta$-lactam antibiotics began even before the first $\beta$-lactam, penicillin, was developed. The first $\beta$-lactamase was identified in Escherichia coli prior to release of penicillin for use in medical practice [2]. ESBLs were first reported in Klebsiella pneumoniae in 1983, from Germany [3]. Production of beta lactamase is the most common mechanism of antibiotic resistance to beta lactam antibiotics. These are produced by aerobic Gram positive, Gram negative bacteria and also in anaerobes [4]. Because of their increased spectrum of activity, especially against the oxyimino-cephalosporins, these enzymes were called extended- spectrum $\beta$-lactamases (ESBLs) [5].

These enzymes have been derived from TEM and SHV genes by mutations and have been well described in family Enterobacteriaceae especially Klebsiella pneumoniae [6]. Klebsiella species has rapidly become the most common ESBL producing organism, making it difficult to eradicate this organism from the high risk wards such as intensive care units [6].

\section{Material and Methods}

Bacterial isolates: The study was carried out in Microbiology Laboratory, Government Medical College Hospital, Aurangabad, during June 2012-Dec 2013. A total of 679 consecutive non duplicate clinical isolates of multi- drug resistant Klebsiella pneumoniae isolated from various clinical specimens were included in the study.
The specimens included Pus (371), ET secretion (81), Blood (75), Urine (49), Pleural fluid (32), Sputum (32), other fluids (39). All the samples were processed and isolates identified by standard methods [79].

To determine their multi-drug resistance, antimicrobial susceptibility testing was performed by Kirby-Bauer's disc diffusion method as per Clinical Laboratory Standards Institute-2012 (CLSI) recommendations. Antibiotic discs were procured from Hi-Media Laboratories, Mumbai (India).

All strains of Klebsiella pneumoniae found resistant or intermediate sensitive to the third generation cephalosporin

ns namely cephotaxime, or ceftazidime were tested for the production of ESBL by the following CLSI ESBL SCREENING TEST. Amongst the strains sensitive to these drugs, all were not excluded from tests for ESBL. CLSI has recommended that even if a strain falls in sensitive range ( $\geq 23$ for Cephotoxime and $\geq 18$ for Ceftazidime) some of them could still be ESBL producers. CLSI advises that those strains with zone of inhibition of $\leq 27$ for Cephotoxime and $\leq 22$ for Ceftazidime belong to this group.

${ }^{*}$ Corresponding author: Begum F, Department of Microbiology, Shadan Institute of Medical Sciences, Hyderabad, Affiliated to NTRUHS, Vijayawada, India, Tel:+91 9441040580; E-mail: fouzia.micro@gmail.com

Received December 11, 2014; Accepted April 11, 2015; Published April 13, 2015

Citation: Fouzia B, Damle AS (2015) Prevalence and Characterization of Extended Spectrum Beta- Lactamase Production in Clinical Isolates of Klebsiella pneumonia. J Med Microb Diagn 4: 182. doi:10.4172/21610703.1000182

Copyright: (C) 2015 Fouzia B, et al. This is an open-access article distributed under the terms of the Creative Commons Attribution License, which permits unrestricted use, distribution, and reproduction in any medium, provided the original author and source are credited. 
As a screening test, isolates showing inhibition zones $\leq 27 \mathrm{~mm}$ for Cefotaxime, $\leq 22 \mathrm{~mm}$ for Ceftazidime were selected as potential ESBL producers. Extended spectrum beta lactamase detection in Klebsiella pneumoniae isolates positive by screening test was confirmed by phenotypic confirmatory disk diffusion test (PCDDT). In brief it is as follows. Disk of cephotaxime and ceftazidime alone and those containing a combination of Clavulanic acid with these antibiotics were used as per CLSI guidelines. Following control strains were used for ESBL detection.

\section{Positive control for ESBL Klebsiella pneumoniae ATCC: 700603.}

Negative control for ESBL- Escherichia coli ATCC: 25922.

Interpretation: Organism was considered ESBL producer if there was more than $5 \mathrm{~mm}$ increase in zone diameter for Ceftazidime and Cefotaxime tested in combination with Clavulanic acid versus its zone when tested alone [10]. Some of the phenotypic tests for detection of ESBLs are: Double Disc Synergy test, three dimensional test, Inhibitor potentiated disc diffusion test, Disk approximation test, Vitek ESBL test and $\mathrm{E}$ test [11].

Molecular detection tests include: DNA probes (specific for gene family e.g., TEM or SHV.) PCR (Easy to perform, specific for gene family e.g. TEM or SHV) Oligotyping (Detects specific TEM variants) PCR-RFLP (Easy to perform, can detect specific nucleotide changes) PCR-SSCP (can distinguish between a number of SHV variants) LCR (can distinguish between a number of SHV variants) Nucleotide sequencing (The gold standard, can detect all variants) [5].

For detection of ESBL genes, PCR was performed using the following two different sets of primers. Set 1 had primers labeled as TEM and SHV. (Table 1) The strains under study were subjected to PCR separately using these primers. Set 2 had primers labeled bla and $\mathrm{bla}_{\mathrm{SHV}}$ (Table 1). The strains under study were subjected to PCR separately using these primers also. In addition multiplex PCR was also performed with these two sets (TEM and SHV; $b_{a_{\mathrm{TEM}}}$ and $\mathrm{bla}_{\mathrm{SHV}}$ ). Thus for set1 TEM, SHV and multiplex PCR was performed. Similarly for set $2 \mathrm{bla}_{\mathrm{TEM}}, \mathrm{bla}_{\mathrm{SHV}}$ and multiplex PCR was performed. All primers were synthesized by Merck-Bangalore, India.

The primers of setlused to amplify TEM gene correspond to the position 55 to 75 and 752 to 771 respectively, with 717 bp fragment size. Primers to amplify SHV gene correspond to position 509 to 526 and 962 to 979 respectively with a fragment size of $471 \mathrm{bp}$. The primers of set 2 are used to amplify $867 \mathrm{bp} \mathrm{bla}_{\mathrm{TEM}}$ and $930 \mathrm{bp} \mathrm{bla}_{\mathrm{SHV}}$ coding region in Klebsiella pneumoniae.

\section{Preparation of DNA}

Colony PCR of Clinical isolates were performed for screening the resistance genes using TEM, SHV, bla ${ }_{\mathrm{TEM}}$ and $\mathrm{bla}_{\mathrm{SHV}}$ primers. For colony PCR bacterial isolates were grown overnight on LB agar. A colony of

\begin{tabular}{|l|l|l|}
\hline Target & Primer sequence(5'-3') & Product size (bp) \\
\hline SHV F & TCAGCGAAAAACACCTTG & 471 \\
\hline SHV R & TCCCGCAGATAAATCACC & 717 \\
\hline TEM F & CTTCCTCCTGTTTTTGCTCACCCA & \\
\hline TEM R & TACGATACGGGAGGGCTTAC & 867 \\
\hline bla $_{\text {TEM }}$ F & ATAAAATTCTTGAAGACGAAA & \\
\hline bla $_{\text {TEM }}$ R & GACAGTTACCAATGCTTAATCA & 930 \\
\hline bla $_{\text {SHV }}$ F & GGGTTATTCTTATTTGTCGC & \\
\hline bla $_{\text {SHV }}$ R & TTAGCGTTGCCAGTGCTC & \\
\hline F: Forward; R: Reverse & \\
\hline
\end{tabular}

Table 1: Primers used for detection with their expected fragment sizes1 [5], 2 [10]. each isolates were suspended in $100 \mu$ d double distilled water and boiled at $95^{\circ} \mathrm{C}$ for $10 \mathrm{~min}$. Following centrifugation at $10,000 \mathrm{rpm}$ for $1 \mathrm{~min}$ the supernatant was used as the crude DNA.

Amplification of TEM and SHV genes (set 1) were performed in a $25 \mu \mathrm{l}$ volume containing 3.5 $\mathrm{l}$ PCR master mix (Merck, Bangalore, India), $0.5 \mu \mathrm{l}$ each forward and reverse primers. $5 \mu \mathrm{l}$ template DNA preparation was added to the reaction mixture. PCR amplifications were carried out in a Peltier Thermal Cycler (PTC-200, MJ Research, USA).

The cycling conditions for amplification were as follows [6]. For SHV gene, initial denaturation at $94^{\circ} \mathrm{C}$ for 2 min and 30 cycles of $1 \mathrm{~min}$ at $94^{\circ} \mathrm{C}, 30 \mathrm{sec}$ at $52^{\circ} \mathrm{C}$ and $45 \mathrm{sec}$ at $72^{\circ} \mathrm{C}$, followed by $5 \mathrm{~min}$ at $72^{\circ} \mathrm{C}$.

For TEM gene, cycling conditions were as follows [6]. Initial denaturation of $2 \mathrm{~min}$ at $94^{\circ} \mathrm{C}$ and 30 cycles of $1 \mathrm{~min}$ at $94^{\circ} \mathrm{C}, 1 \mathrm{~min}$ at $58^{\circ} \mathrm{C}$ and $1 \mathrm{~min}$ at $72^{\circ} \mathrm{C}$, followed by $7 \mathrm{~min}$ at $72^{\circ} \mathrm{C}$.

The resulting PCR products were analyzed by electrophoresis with $1.5 \%$ agarose gel in Tris-borate-EDTA buffer. The gels were stained with ethidium bromide and band observed were photographed on an UV trans illuminator. A molecular weight standard (100bp ladder-Merck, Bangalore) was included on each gel.

For set 2, reactions were performed in a Peltier Thermal Cycler (PTC-200, M J Research, USA), according to the protocol [11]. For both $\mathrm{bla}_{\mathrm{TEM}}$ as well as $\mathrm{bla}_{\mathrm{SHV}}$ PCR profile was an initial denaturation at $94^{\circ} \mathrm{C}$ for $5 \mathrm{~min}$ followed by $35 \mathrm{cycles}$ of $94^{\circ} \mathrm{C}$ for one min, $52^{\circ} \mathrm{C}$ for one min and $72^{\circ} \mathrm{C}$ for $10 \mathrm{~min}$. PCR products were analyzed by electrophoresis with 1.5 per cent agarose gel. After staining with ethidium bromide the gel was observed on trans illuminator and the image was recorded. In an earlier study [12] same cycling conditions were used for PCR when bla $\mathrm{T}_{\mathrm{TEM}}$ and $\mathrm{bla}_{\mathrm{SHV}}$ were amplified separately. Hence we performed multiplex PCR using same primers (set 2) and followed same cycling conditions.

\section{Results}

Antibiotic resistance pattern was as follows: Gentamicin (79.23\%), Amikacin (65.53\%), Ciprofloxacin (68.92\%), Cefotaxime $(85.12 \%)$, Ceftazidime (83.21\%), Cefipime (82.32\%), and Meropenem (17.37\%).

It was observed that many $(\geq 80 \%)$ of our isolates of Klebsiella pneumoniae were resistant to third generation Cephalosporin's and other antibiotics, making them Multi Drug Resistant (MDR) strains. Most of these were isolated from in-patients, indicating probable Hospital Acquired Infection.(HAI)

Out of 679 strains of Klebsiella pneumoniae, 35 strains were sensitive to 3GC. All others i.e. 644 (94.84\%) strains were subjected to PCDDT. Of these 644 strains, 612 strains showed increase in zone diameter of $5 \mathrm{~mm}$ to the combination of Cefotaxime + Clavulanic acid when compared to Cefotaxime alone. Same 612 strains gave similar results with Ceftazidime + Clavulanic acid when compared to Ceftazidime alone. All these 612 (90.13\%) strains were reported as ESBL producers. (Figure 1) Of the 612 ESBL positive clinical isolates, 100 random isolates were subjected to genotypic characterization by PCR for presence of TEM and SHV gene (Table 2). With Primer Set: 1- All the hundred isolates $(100 \%)$ showed presence of TEM gene, while forty isolates (40\%) showed presence of SHV gene. Thus forty isolates contained both TEM and SHV genes (40\%). Sixty isolates (60\%) had only TEM gene. No isolates showed SHV gene alone (Figure 2) With Primer Set: 2 Amplification with bla $\mathrm{TEM}_{\mathrm{TEM}}$ and bla $\mathrm{SHV}_{\mathrm{S}}$ seventy isolates (70\%) showed presence of TEM gene with bla $\mathrm{TEM}_{\text {primers, while fifty isolates }(50 \%)}$ 
Citation: Fouzia B, Damle AS (2015) Prevalence and Characterization of Extended Spectrum Beta-Lactamase Production in Clinical Isolates of Klebsiella pneumonia. J Med Microb Diagn 4: 182. doi:10.4172/21610703.1000182

showed presence of SHV gene with bla ${ }_{\mathrm{SHV}}$ primers. Twenty isolates (20\%) had both bla $\mathrm{TEM}_{\mathrm{TE}}$ and $\mathrm{bla}_{\mathrm{SHV}}$ gene (Figure 3 and Table 3 )

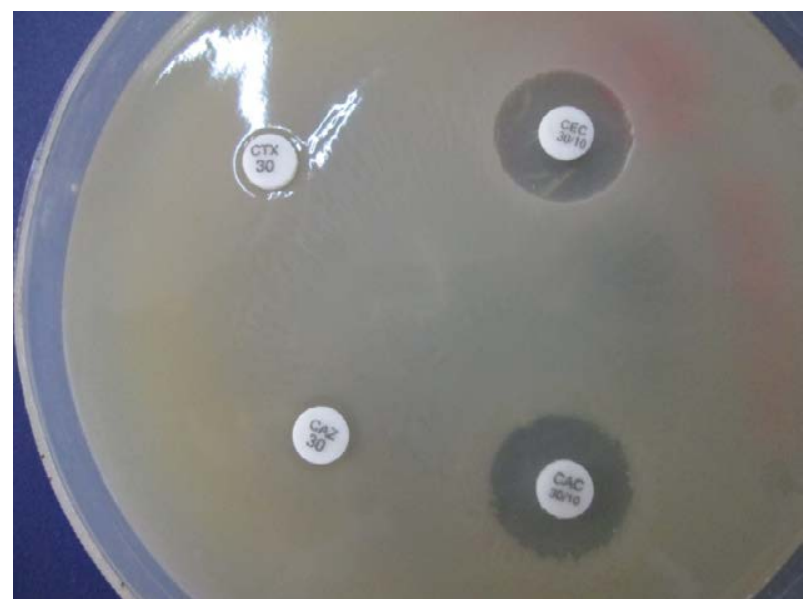

Figure 1: Phenotypic Confirmatory Disc Diffusion Test (PCDDT): Ceftazidime and Cefotaxime showing an increase in zone diameter of $>5 \mathrm{~mm}$ with the addition of Clavulanic acid, indicative of ESBL production in a Klebsiella pneumoniae isolate.

\begin{tabular}{|l|l|l|}
\hline & Multiplex TEM+SHV (Set 1) & $\begin{array}{l}\text { Multiplex bla } \\
\text { (Set 2) }\end{array}$ \\
\hline $\begin{array}{l}\text { Number of Isolates having } \\
\text { both markers }\end{array}$ & $70 \%$ & $30 \%$ \\
\hline $\begin{array}{l}\text { Number of Isolates having } \\
\text { unique marker-TEM }\end{array}$ & $30 \%$ & $50 \%$ \\
\hline $\begin{array}{l}\text { Number of Isolates having } \\
\text { unique marker -SHV }\end{array}$ & Nil & $20 \%$ \\
\hline
\end{tabular}

Table 2: Showing the percentage of isolates amplified using multiplex PCR.

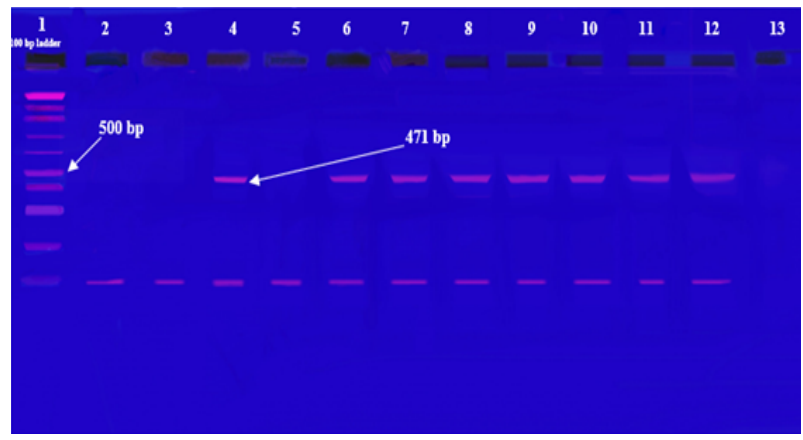

Figure 2: Multiplex PCR using TEM and SHV primer.

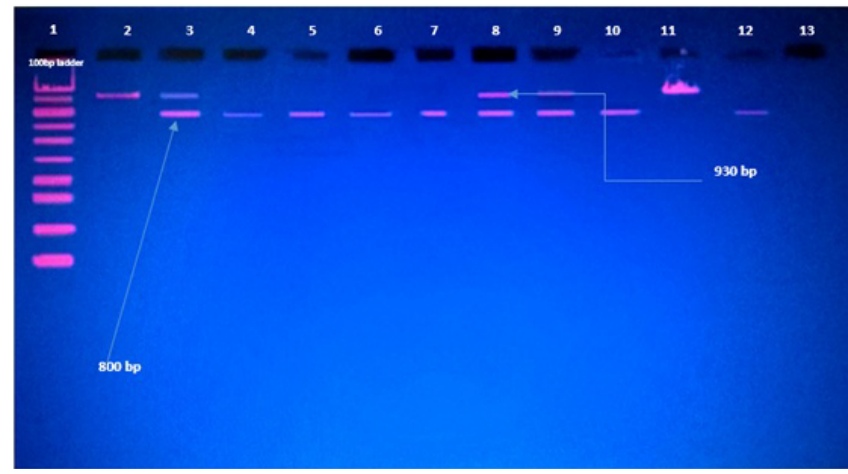

In the above figure lane 1 is $100 \mathrm{bp}$ ladder, lane 2-11 are samples, lane 12 positive control and lane 13 negative control.

Figure 3: Primer set 2-Multiplex amplification with $\mathrm{bla}_{\mathrm{TEM}}$ and $\mathrm{bla}_{\mathrm{SHV}}$.

\section{Discussion}

Amongst GNBs, common organisms having ESBL production are Klebsiella pneumoniae and E.coli. Of these Klebsiella pneumoniae species has gained importance due to high proportion of strains showing ESBL production. Hence we concentrated our study only to Klebsiella pneumoniae.

Klebsiellae are opportunistic pathogens and can give rise to severe diseases such as septicaemia, pneumonia, UTI, and soft tissue infection. Typically, Klebsiella infections are nosocomial. The hospitalized, immune compromised patient with underlying diseases is the main target of these bacteria. Thus, Klebsiella infections may serve as a paradigm of hospital-acquired infections [13].

In the last 12 years ESBL have gone from being an interesting scientific observation to a reality of great medical importance. Initially restricted to the hospital acquired infections, they have also been isolated from infections in outpatients. Major outbreaks have been reported from all over the world thus making them emerging pathogens.

In some center's like Ujjain, Bijapur, Kanchipuram (some of the cities in India) the incidence of ESBLs is still very low [14-16]. But in metropolitan cities (of India) like New Delhi there is gradual increase in ESBL producers, from $80 \%$ in 2002, 91\% in 2005, 97\% in 2007 and $100 \%$ in 2010 [17-19].This probably relates to rampant and inadvertent use of third generation cephalosporin's). Over the counter availability could be another cause when patients resort to self-medication [20]. Two studies from Chennai in 2006show different rates of ESBLs [21,22]. Similarly two studies in 2012 from Davangere show different rates of

\begin{tabular}{|c|c|c|c|c|c|c|}
\hline $\begin{array}{l}\text { ESBL positive } \\
\text { clinical isolates }\end{array}$ & TEM(100 bp ) & SHV(471 bp) & Multiplex TEM+SHV & blaTEM(800 bp) & blaSHV(930bp) & Multiplex bla $\mathrm{TEM}_{\mathrm{TE}}+\mathrm{bla}_{\mathrm{SHV}}$ \\
\hline 1 & + & & & & + & \\
\hline 2 & + & & & + & + & + \\
\hline 3 & + & + & + & + & & \\
\hline 4 & + & & & + & & \\
\hline 5 & + & + & + & + & & \\
\hline 6 & + & + & + & + & & \\
\hline 7 & + & + & + & + & + & + \\
\hline 8 & + & + & + & + & + & + \\
\hline 9 & + & + & + & + & & \\
\hline 10 & + & + & + & & + & \\
\hline 11 & + & + & + & + & & \\
\hline
\end{tabular}

Table 3: Showing PCR amplification of TEM and SHV genes among the random few ESBL positive clinical isolates. 
ESBLs. It has been already reported that incidence of ESBLs differs not only across the country but from institute to institute $[23,24]$.

The incidence of ESBLs in Manipal has actually decreased over the years. From $41 \%$ in 2007; it has decreased to $27.39 \%$ in $2009[25,26]$. They developed quick screening methods to assess the different mechanisms of ESBL production, so that the patients can be treated with appropriate antibiotics. Prevalence of ESBLs is reported to be high from Medicine ICU, Surgery wards and NICU/ Pediatric wards [17,2730]. Our study correlates with these studies. The exact reason for this cannot be pointed out. But probably it relates to drug prescribing habits of these wards [31].

There was an increasing trend of rate of ESBLs in China. In was $33.3 \%$ in $2005,41 \%$ in 2006 and $57 \%$ in 2007 [32]. It was further increased to $77.8 \%$ in 2009 [33]. ESBL production of Klebsiella pneumoniae from Thailand ranged from 44.4\%-100\% [34,35] and Korea 30\% [36]. Another Asian Country Iran showed an increase in ESBL production by Klebsiella pneumoniae of $52.5 \%$ in 2008 [37] to $59.2 \%$ in 2009 [38], reaching $96 \%$ by 2010 [39]. A study from Nigeria recovered Klebsiella pneumoniae from patients suspected to have urinary tract infections; $35.3 \%$ were ESBL producers [40]. From Sharjah, UAE, found $40 \%$ of Klebsiella isolates as ESBL producers [41]. In a study from Cairo, Egypt ESBLs were detected in $55.3 \%$ of Klebsiella pneumoniae [42]. Riyadh, Saudi Arabia reported 55\% of Klebsiella pneumoniae as ESBL producers [43]. From Pakistan urinary tract infections caused by ESBL producing Klebsiella pneumoniae was 71.7\% [44]. Patients having infections caused by ESBL producing organisms are at increased risk of treatment failure with broad spectrum $\beta$-lactam antibiotics. Therefore, it is recommended that any organism confirmed for ESBL production be reported as resistant to all broad-spectrum $\beta$-lactam antibiotics, regardless of the susceptibility test result [10].

With the spread of ESBL producing strains in hospitals all over the world, it is necessary to know the prevalence of ESBL positive strains in a hospital so as to formulate a policy of empirical therapy in high risk units where infections due to resistant organisms is much higher [17].

In the present study, it was observed that ESBL positive isolates exhibited high levels of multidrug resistance and the prevalence of ESBL producing Klebsiella pneumoniae was found to be high (90.13\%). Similar results were achieved by other studies $[6,18]$.

From India high prevalence of ESBL producing Klebsiella strains has been reported by various groups. Reported frequency of ESBL producing Klebsiella species in India ranged from $14-100 \%[16,19]$. Prevalence of ESBL producing Klebsiella around the world varies between $3 \%-8 \%$ to $100 \%$ [35,45]. The easiest approach to genetic detection of $\beta$-lactamases is the amplification of the whole $\beta$-lactamase (bla) gene or its parts using PCR with oligonucleotide primers that are specific for the target gene. They can be helpful in providing explanations for unusual complex antibiograms, confirming specific resistance mechanisms

Out of the 679 isolates, majority of ESBL producers were from urine (97.87\%) followed by pleural fluid (96.87\%) and other fluids $(94.73 \%)$ Isolates from urinary samples were found to be maximum. This could be due to injudicious use of antibiotics in patients suffering with recurrent urinary tract infections and persistent use of indwelling catheters in Intensive Care Unit patients. In the present study, all the ESBL producers were found resistant to 2 or more drugs, whereas multidrug resistance in non ESBL producers was comparatively less. Our study showed that ESBL production was high among uropathogens, and that the ESBL producers were mostly multi drug resistant. The situation is worsened due to increased multidrug resistance seen in ESBL producers [46]

Monitoring of ESBL production and antimicrobial susceptibility testing are necessary to avoid treatment failure in patients with UTI. ESBL producers are associated with increased morbidity and mortality. The majority of ESBL producing $K$. pneumoniae were resistant to the common antibiotics used in the treatment of urinary tract infections. The early detection and reporting of suitable antibiotics can reduce the treatment failure in ESBL UTI [44].

An increasing number of endemic and epidemic outbreaks in paediatric wards have been reported. Especially common are Klebsiella infections causing septicaemia and meningitis in newborns in neonatal intensive care units. Since more and more of these outbreaks have been caused by multidrug-resistant strains, Klebsiella neonatal infections are becoming a major concern of the paediatrician. Especially peculiar has been the repeated frequent isolation of multidrug-resistant Klebsiella isolates. The incidence of ESBL-producing strains among clinical Klebsiella isolates has been steadily increasing over the past several years. Currently, the available data suggest a further increase in the incidence of ESBL-producing isolates. As a result, the therapeutic options are becoming limited, so that in the near future there will be an urgent need for hospital infection control measures that counter the spread of ESBL-producing bacteria [13].

Carbepenems are often the last line of effective treatment available for infections caused by MDR Enterobacteriaceae [47]. In the present study $17.37 \%$ isolates were resistant to Meropenem, which correlates with another study [48]. Meropenem is a substrate for the multidrug efflux system. Overexpression of this efflux system raises the MIC of Meropenem and other substrate antibiotics, but not Imipenem. In the presence of a $\beta$-Lactamase or reduced permeability from down regulation of a critical outer membrane protein, frank resistance to Meropenem can occur [49]. The incidence of carbapenem resistance in E.coli and K. Pneumoniae isolates reveals the most serious threat to the clinician. Increasing resistance to carbepenems and the event of superbug in Indian hospitals and community has now spurred the government and regulatory agencies to impose strict statutory guidelines for rational use of antibiotics [50]. We have used two phenotypic methods for detection of ESBL production. One screen and other PCDDT. Out of the total 679 isolates, 644 strains were ESBL positive by screening test. When these $644 \mathrm{ESBL}$ screen positive isolates were subjected to PCDDT, 612 were confirmed to be ESBL producers (90.13\%). This means that the screening test gives some (4.96\%) false positives or there may be other mechanisms of resistance to 3GC. Put together overall the TEM+SHV primers (Set 1) are more effective in revealing the presence of the resistance gene as compared to bla + bla $_{\mathrm{SHV}}$ primer (Set 2). We found that multiplex PCR was successful in amplifying both the resistance genes targeted in this study. As the primer combination is effectively covering $100 \%$ of the resistant isolates which were tested in the amplification study, multiplexing can thus be efficiently used for diagnosing the resistant strains. However in institutes where PCR facilities are not available, PCDDT appears to be a good phenotypic confirmatory test for detecting ESBL production. Studies from other parts of the world reported that SHV gene was common in Klebsiella pneumoniae isolates [6]. A study from Tanzania showed SHV to be more prevalent than TEM [51], similarly in another study from Germany TEM was present in $100 \%$ isolates and SHV in $80 \%$. [52]. Whereas studies from China [33] Korea [36] and India [12,53] reported TEM to be more prevalent than SHV.

Considering these findings, present study and other Indian studies 
Citation: Fouzia B, Damle AS (2015) Prevalence and Characterization of Extended Spectrum Beta-Lactamase Production in Clinical Isolates of Klebsiella pneumonia. J Med Microb Diagn 4: 182. doi:10.4172/21610703.1000182

Page 5 of 6

referred to above, it appears that TEM is more prevalent in Asia. Genetic studies can be helpful in providing explanations for unusual complex antibiograms, confirming specific resistance mechanisms and epidemiological studies in a geographical area.

\section{Conclusion}

Reporting of ESBL producing isolates from clinical samples is useful for the clinicians to select appropriate antibiotics for the treatment of ESBL producing strains and to take proper precaution to prevent the spread of these resistant organisms to other patients.

The routine susceptibility test done by clinical laboratories fail to detect ESBL positive strains and can erroneously detect isolates sometimes to be sensitive to any of the third generation cephalosporin's, hence a special phenotypic confirmatory test is indispensable for detecting ESBLs. PCDDT is a good phenotypic confirmatory test.

Thus the high level of ESBLs among Klebsiella pneumonia isolates is alarming and warrants special attention from clinicians and Microbiologists. We as Microbiologists should readily identify these isolates, so that proper therapy can be instituted to avoid misuse or overuse of antibiotics.

Rapid diagnosis can be done by using the PCR amplification without the need for phenotypic characterization.

Multiplex PCR can be used as a rapid method to identify common genes (TEM and SHV) responsible for extended spectrum beta lactamase production in Klebsiella pneumonia isolated from different clinical samples. It will prove valuable for surveillance and for determining the line of treatment against drug resistant organisms, thus saving precious time and resources.

The TEM+SHV primers (Set: 1) were more effective in revealing the presence of the resistance gene as compared to $\mathrm{bla}_{\mathrm{TEM}}+\mathrm{bla}_{\mathrm{SHV}}$ primer (Set: 2) combination.

\section{Refereneces}

1. Greenwood D (1998) Resistance to antimicrobial agents a personal view. J Med microbial 47: 751-52.

2. Abraham EP, Chain E (1940) An enzyme from bacteria able to destroy penicillin Nature 146-837.

3. Knothe H, Shah P, Krcmery V, Antal M, Mitsuhashi S (1983) Transferable resistance to cephotaxime, cefoxitin, cefamandole and cefuroxime in clinical isolates of Klebsiella pneumoniae and Serratia marcescens. Infection 11: 315318.

4. Louis Rice CHEST 2001; 119: 391S-396S.

5. Bradford P.A (2001) Extended- Spectrum Beta Lactamases in the $21^{\text {st }}$ Century: Characterization, epidemiology, and detection of this important resistance threat. Clin Microbiol Rev 14: 933-951.

6. Lal P, Kapil A, Das BK, Sood S (2007) Occurrence of TEM and SHV gene in extended Spectrum $\beta$-Lactamases (ESBLS) producing Klebsiella sp. Isolated from a tertiary care hospital. Indian J Med Res 125: 173-178.

7. Cheesbrough Monica (2000) Microbiological tests. In: district laboratory practice in tropical countries. Cambridge, USA.

8. Koneman EW, Allen SD, Janda WM, Schreckenberger PC, Win WC. Colour atlas and Textbook of Diagnostic Microbiology. (5thedn), JB Lippincott co.

9. Baveja CV (2012) Textbook of Microbiology. (4thedtn), Arya Publications.

10. http: //antimicrobianos.com.ar/ATB/wp-content/uploads/2012/11/M100S22E.pdf.

11. Chaudhary U, Aggarwal R (2004) Extended spectrum $\beta$-lactamases (ESBLs)An emerging threat to clinical therapeutics. Ind J Med Microbiol 22: 75-80.

12. Jain A, Mondal R (2008) TEM and SHV genes in extended spectrum beta lactamase producing Klebsiella species and their antimicrobial resistance pattern. Ind J Med Res 128: 759-64.

13. Podschun R, Ullmann U (1998) Klebsiella spp. as Nosocomial Pathogens: Epidemiology, Taxonomy, Typing Methods, and Pathogenicity Factors. Clin Microbiol Rev 11: 589-603.

14. Pathak A, Marothi Y, Kekre V, Mahadik K, Macaden R, et al. (2012) High prevalence of extended spectrum $\beta$-lactamases producing pathogens: results of a surveillance study in two hospitals in Ujjain India. Dove Press Journal Infection and Drug Resistance 5: 65-73.

15. Metri BC, Jyothi P, Peerapur BV (2011) The Prevalence of ESBL among Enterobacteriaceae in a tertiary care hospital of North Karnataka, India. J Clin Diag Res 5: 470-475.

16. Kumar MS, Lakshmi V, Rajagopalan R (2006) Occurrence of extended spectrum $\beta$-lactamases among Enterobacteriaceae spp isolated at a tertiary care institute. Ind J Med Microbiol 24: 208-11.

17. Mathur P, Kapil A, Das B, Dhawan B (2002) Prevalence of extended spectrum beta lactamase producing Gram negative bacteria in a tertiary care hospital. Ind J Med Res 115: 153-157.

18. Wattal C, Chugh TD, Sharma A, Oberoi JK, Prasad KJ, et al. (2005) ESBL - An Emerging Threat to antimicrobial Therapy. Microbiology Newsletter Sir Ganga Ram Hospital 10: 8.

19. Rastogi V, Nirwan PS, Jain S, Kapil A (2010) Nosocomial outbreak of septicaemia in neonatal intensive care unit due to extended spectrum $\beta$-lactamase producing Klebsiella pneumoniae showing multiple mechanisms of drug resistance. Ind J Med Microbiol 28: 380-4.

20. Fouzia B, Damle AS (2015) Genotypic detection of extended-spectrum B-lactamase-producing Klebsiella pneumoniae in a Tertiary care hospital. International Journal of Biomedical and Advance Research (IJBAR) 6: 91-97.

21. Menon T, Bindu T, Kumar CPG, Nalini S, Thirunarayan MA (2006) Comparison of double disc and three dimensional methods to screen for ESBL producers in a tertiary care hospital. Ind J Med Microbiol 24: 117-120.

22. Padma M, Lokeshwari TS, Uma S, Vijaylakshmi K (2006) Prevalence of extended spectrum $\beta$-lactamase resistance among bacteria causing hospital infections- detection using PCR. Sri Ramachandra J. Med 1.

23. Eshwar Singh R, Raghukumar KG, Veena M (2012) ESBL production: Resistance pattern in Escherichia coli and Klebsiella pneumoniae. A study of NCCLS method. Research Journal of Pharmaceutical, Biological and Chemical Sciences (RJPBCS) 3: 559-565.

24. Archana S, Mirdula RP, Veena M, Eshwar Singh, Basavaraj KN et al. (2012) ESBL - A continuous diagnostic challenge to clinical microbiology Laboratories. International Journal of Applied and Pharmaceutical Technology ( I J A B P T) 3: 9-15.

25. Shobha KL, Gowrish RS, Sugandhi R, Sreeja CK (2007) Prevalence of Extended spectrum beta lactamases in urinary isolates of Escherichia coli, Klebsiella and Citrobacter species and their antimicrobial susceptibility pattern in a tertiary care hospital. Ind J for the practicing Doctor 3.

26. Shobha KL, Ramachandra L, Rao G, Majumdar S, Rao SP (2009) Extended spectrum Beta-lactamases (ESBL) in Gram Negative bacilli at a tertiary care hospital. Journal of Diagnostic and clinical Research 3: 1307-1312.

27. Krishna BVS, Asha BP, Chandrasekhar MR (2007) Extended Spectrum $\beta$-Lactamase producing Klebsiella pneumoniae in Neonatal Intensive Care Unit. Indian J Pediatr 74: 627-630.

28. Baby PS, Appalaraju B (2004) Extended spectrum $\beta$-lactamases in urinary isolates of Escherichia coli and Klebsiella pneumoniae. Prevalence and susceptibility pattern in a tertiary care hospital. Indian. J Med Microbiol 22: 172 174.

29. Peer MA, Manzoor AT, Bashir AF, Kaiser A (2010) Extended spectrum $\beta$-lactamase producing Klebsiella pneumoniae at a tertiary care setup in Kashmir, India: comparative phenotypic detection and antimicrobial susceptibility pattern. Reviews In Infection 1: 124-133.

30. Nandan K, Dey S, Kumar D, Sen A, Ganguly U (2012) Extended spectrum $\beta$-lactamses production amongst gram negative bacilli isolated from patients attending a tertiary care hospital in Eastern Bihar. Journal of evolution of Medical and Dental sciences 1: 430-435.

31. Fouzia B, Damle AS (2015) Prevalence of bla ${ }_{\mathrm{TEM}}$ AND bla $\mathrm{s}_{\mathrm{SHV}}$ genes in clinical Isolates of Klebsiella pneumoniae in a tertiary care hospital Scholars Research Library: Journal of Microbiology and Biotechnology Research 5: 1-7. 
Citation: Fouzia B, Damle AS (2015) Prevalence and Characterization of Extended Spectrum Beta-Lactamase Production in Clinical Isolates of Klebsiella pneumonia. J Med Microb Diagn 4: 182. doi:10.4172/21610703.1000182

32. Huang H, Li JC, Hui NZ (2009) Study of infection and antimicrobial resistance of extended spectrum and $\beta$ - lactamases from paediatrics. Chinese journal of Microbiology 6: 547-549.

33. Feng SW, JUN Z, Ping QIJ (2009) Transconjugation and genotyping of the plasmid meadiated Ampc $\beta$ - lactamase and extended spectrum $\beta$ - lactamase genes in klebsiella pneumonia. Chin Med J 122: 1092-1096.

34. Jitsurong S, Yodsawat J (2006) Prevalence of Extended-Spectrum BetaLactamases (ESBLs) produced in Blood Isolates of Gram Negative Bacteria in A Teaching Hospital in southern Thailand. South East. J Trop Med Public Health 37.

35. Chanwit T, Somporn S, Wararat C (2007) A correlation between phenotypes and genotypes of extended spectrum beta lactamase (ESBL) producing Klebsiella pneumoniae in a university hospital, Thailand. J infect Dis Antimicrob Agent 24: 117-23.

36. Jeong SH, Bae IK, Lee JH, Sohn SG, Kang GH, et al. (2004) Molecula characterization of extended spectrum beta lactamases produced by clinical isolates of Klebsiella pneumoniae and Escherichia Coli from a Korean Nationwide survey. J Clin Microbiol 42: 2902-6.

37. Aminzadeh Z, Kashi MS, Shabani M (2008) Bacteruria by extended spectrum beta lactamase producing Escherichia coli and Klebsiella pneumoniae in a Government Hospital of Tehran, Iran. Iranian Journal of Kidney Diseases 2 197-200.

38. Bazzaz BSF, Naderinasab M, Mohamadpoor AH, Farshadzadeh Z, Ahmadi S et al. (2009) The prevalence of extended spectrum beta lactamase producing Eschericha coli and Klebsiella pneumoniae among clinical isolates from general hospital in Iran. Acta Microbiologica et Immunologica Hungarica 56: 89-99.

39. Leila N, Fereshteh S, Vajihe SN, Shoeib N (2010) PER, CTX-M, TEM and SHV Beta-lactamases in clinical isolates of Klebsiella pneumoniae isolated from Tehran, Iran. Iranian J Basic Med Sci 13: 111-118.

40. Olonitola OS, Olayinka AT, Inabo HI, Shaibo AM (2007) Short communication: Production of extended spectrum beta lactamases of urinary isolates of Escherichia coli and Klebsiella pneumoniae in Ahmadu Bello University Teaching hospital, Zavia, Nigeria. International Journal of Biological and chemical sciences 1: 181-185.

41. Mansour AZ, Abiola S, Fatima R, Shaikha MAJ, Debatta P (2008) Prevalence and Antimicrobial susceptibility pattern of extended spectrum beta lactamase producing Enterobacteriaceae in the united Arab Emirates. Med Princ Prac. 17: 32-37.
42. Nevine SF, Mervet M, El-Damorawy (2008) CTX-M Extended spectrum beta lactamases detected from intensive care unit of an Egyptian Medical Research Institute. Research. J Med Microbial Sciences 3: 84-91.

43. Mohammed HM, Shibl AM, Tawfik AF (2009) Prevalence and molecular characterization of extended spectrum $\beta$-lactamase producing Klebsiella pneumoniae in Riyadh, Saudi Arabia. Ann Saudi Med. 29: 253-57.

44. Hasan E, Ikram OH, Aizza Z, Saqib M, Muhammed MJ (2011) Urinary tract infections caused by extended spectrum $\beta$-lactamase (ESBL) producing Escherichia coli and Klebsiella pneumonia. African Journal of Biotechnology 10: 16661-16666.

45. Ferreira CM, Ferreira WA, Almeida NC, Naveca FG, Barbosa Md (2011) Extended-spectrum beta-lactamase producing bacteria isolated from Haematologic patients in Manaus, State of Amazonas, Brazil. Brizilian. J Microbiology 42: 1076-1084.

46. Tankhiwale SS, Jalgaonkar SV, Sarfraz A, Umesh H (2004) Evaluation of extended spectrum beta lactamases in urinary isolates. Indi J Med Res 120: 553-556.

47. Pitout JD (2010)The latest threat in the war on antimicrobial resistance. Lancet Infect Dis 10: $578-9$.

48. Rampure R, Gangane R, oli AK, Kelvani CR (2013) Prevalence of MDR-ESBL producing Klebsiella pneumoniae isolated from clinical samples. J Microbio Biotech Res 3: 32-39.

49. Mandell GL, Bennet JE, Dolin R (2005) Principles and practice of infectious diseases. (6thedn), Elsevier, Churchill, Livingstone.

50. Bora A, Hazarika NK, Shukla SK, Prasad KN, Sarma JB, et al. (2014) Prevalence of bla $\mathrm{b}_{\mathrm{TEM}}, \mathrm{bla}_{\mathrm{SHV}}$ and bla $\mathrm{b}_{\mathrm{CT}}-\mathrm{M}$ genes in clinical isolates of Escherichia coli and Klebsiella pneumoniae from Northeast India. Indian journal of Pathology and Microbiology 7: 249-254

51. Ndgulile F, Jureen R, Harthug S, Urassa W, Langeland N (2005) Extended spectrum $\beta$-lactamases among Gram negative bacteria of nosocomial origin from an intensive care unit of a tertiary health facility in Tanzania. BMC Infectious Diseases 5: 86.

52. Schmit J, Jacobs E, Schmidtt H (2007). Molecular characterization of extended spectrum beta-lactamases in Enterobacteriaceae from patients of two hospitals in Saxony, Germany. J Med Microbiol 56: 241-249.

53. Sharma J, Sharma M, Ray P (2010) Detection of TEM and SHV genes in Escherichia coli and Klebsiella pneumoniae isolates in a tertiary care hospita from India. Ind J Med Res 132: 332-336. 